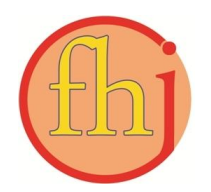

Faletehan Health Journal, 6 (1) (2019) 25-29

www. journal.Ippm-stikesfa.ac.id/ojs/index.php/FHJ

ISSN 2088-673X | e-ISSN 2597-8667

\title{
Risiko Kejadian Karies Gigi Ditinjau dari Konsumsi Makanan Kariogenik pada Anak Usia Sekolah di Kabupaten Tangerang
}

\author{
Karina M egasari Winahyu ${ }^{1 *}$, Ahmad Turmuzi ${ }^{1}$, Fauzan Hakim ${ }^{1}$ \\ ${ }^{1}$ Fakultas IImu Kesehatan, Universitas M uhammadiyah Tangerang, Banten, Indonesia \\ *Corresponding Author: karinawinahyu@yahoo.com
}

\begin{abstract}
Abstrak
Karies gigi pada anak usia sekolah merupakan masalah kesehatan yang sering terjadi, tetapi kurang mendapat penanganan yang optimal. Karies gigi yang tidak ditangani dengan baik dalam kondisi lanjut dapat mengakibatkan inflamasi sistemik (SIRS) dan meningkatkan risiko penyakit kronik lainnya. Salah satu faktor yang dapat mempengaruhi terjadinya karies gigi adalah makanan kariogenik yang bersifat manis dan lengket. Tujuan penelitian ini untuk mengetahui hubungan antara konsumsi makanan kariogenik dengan risiko kejadian karies gigi pada anak usia sekolah. Metode penelitian menggunakan desain deskriptif analitik dengan pendekatan cross sectional. Jumlah sampel pada penelitian ini sebanyak 163 anak usia sekolah yang dipilih dengan teknik random sampling. Analisis yang digunakan pada penelitian ini adalah chi-square. Hasil penelitian menunjukkan bahwa terdapat 55,8 \% responden dengan tingkat konsumsi makanan kariogenik dan sebanyak 76,7 \% berisiko tinggi karies gigi. Hasil uji statistik menunjukkan bahwa ada hubungan antara konsumsi makanan kariogenik dan risiko kejadian karies gigi. Rekomendasi hasil penelitian ini menyarankan agar tenaga kesehatan melakukan sosialisasi pencegahan karies gigi pada anak usia sekolah dan orang tua untuk menurunkan tingkat konsumsi makanan kariogenik.
\end{abstract}

Kata Kunci : Anak Usia Sekolah, M akanan Kariogenik, Risiko Karies Gigi.

\begin{abstract}
Dental caries in school-age children is a health problem that often occurs, but lacks optimal treatment. Dental caries that are not treated properly in advanced conditions can result in systemic inflammation (SIRS) might lead to increase the risk of other chronic diseases. One of the factors that can affect the occurrence of dental caries, namely cariogenic foods that are sweet and sticky. The purpose of this study was to determine the relationship between consumption of cariogenic foods and the risk of dental caries in school-aged children. The method in this study used a descriptive analytic design with a cross sectional approach. The number of samples in this study were 163 school-age children selected by random sampling technique. The analysis technique used is chi-square. The results showed that there were $55,8 \%$ respondents who had high level of cariogenic foods consumption and $76,7 \%$ who were at high risk of dental caries. The study analytical statistic showed that there is a relationship between the consumption of cariogenic foods and the risk of dental caries. The study suggests that health care providers need to socialize the prevention of dental caries to parents and school-aged children by reducing the level of cariogenic foods consumption.
\end{abstract}

Keywords : School-aged children, Cariogenic Food, Risk of Dental Caries 


\section{Pendahuluan}

Karies gigi merupakan salah satu masalah kesehatan mulut yang dapat mempengaruhi kesehatan masyarakat. Kejadian karies gigi banyak dialami baik oleh anak-anak maupun orang dewasa (World Health Organization, 2019). Karies gigi umumnya terjadi di negara berkembang dibandingkan di negara maju karena prevalensi karies gigi di negara maju terus menurun, sedangkan di negara berkembang prevalensi cenderung terus meningkat (WHO, 2019). Tingginya angka kejadian karies gigi memerlukan penanganan yang optimal, terutama dalam pencegahan kejadian karies gigi pada anak.

Indonesia merupakan salah satu negara berkembang dengan angka kejadian karies yang cenderung terus meningkat. Kementerian Kesehatan Republik Indonesia (2013) menyebutkan bahwa prevalensi kesehatan gigi dan mulut di Indonesia terhadap tingkat karies gigi sebesar $70 \%$ masalah kesehatan gigi dan mulut yaitu karies gigi, 50\% diantaranya adalah anakanak. Sedangkan Riset Kesehatan Dasar menunjukkan bahwa terjadi peningkatan karies gigi pada penduduk Indonesia yaitu 53,3\% pada tahun 2013 dibandingkan dengan tahun 2007 lalu yaitu 43,4\%. Selain itu Kementrian Kesehatan pada tahun 2013 juga menyebutkan bahwa peningkatan karies gigi terjadi di beberapa provinsi yang berada di Indonesia dengan nilai rata-rata setiap provinsi sebesar 18,1\% (Kementerian Kesehatan RI, 2013).

Banten merupakan salah satu provinsi yang mengalami peningkatan karies gigi yang cukup tinggi. Data Riset Kesehatan Dasar pada 2013 menunjukkan bahwa kejadian karies gigi di Banten pada tahun 2013 sebesar 23,7\% melebihi nilai ratarata setiap provinsi (Kementrian Kesehatan Republik Indonesia, 2013). Karies gigi termasuk 20 besar penyakit yang sering terjadi di Kabupaten Tangerang pada tahun 2010, yaitu sebanyak 7.562 anak yang mengalami karies gigi (Kemenkes, 2013). Oleh karena itu, tingginya angka kejadian karies gigi menunjukkan pentingnya masalah kesehatan mulut agar ditangani dengan optimal untuk mencegah komplikasi kesehatan lainnya.

Dampak dari karies gigi dapat mengakibatkan terjadinya penyakit periodontal, yaitu infeksi kronis pada gusi dan tulang pendukung gigi. Menurut Hasturk dan Katarci (2015), penyakit periodontal dapat mengakibatkan bakteri dan sel imun bertransportasi menuju jaringan atau organ tubuh lain melalui sirkulasi darah. Penyakit periodontal merupakan kondisi inflamasi kronik yang memiliki mekanisme patologis yang sama dengan penyakit inflamasi sistemik lainnya, termasuk meningkatkan penyakit jantung koroner (Hasturk dan Katarci, 2015). Hal ini sejalan dengan penelitian Glodny et al. (2013) bahwa karies gigi merupakan factor yang mempengaruhi peningkatan aterosklerosis dan studi Nugroho (2011) yang mengatakan bahwa penyakit periodontal memiliki hubungan yang bermakna dengan penyakit jantung koroner.

Karies gigi pada anak dapat disebabkan oleh perilaku makan yang kurang baik. Anak usia sekolah biasanya menyukai makanan yang manismanis, seperti permen, coklat, kue-kue, gula dan lain-lain. Makanan kariogenik tersebut termasuk dalam karbohidrat yang mudah menimbulkan karies (Prakoso, 2016). Makanan kariogenik merupakan salah satu penyebab pembentukan plak pada permukaan gigi dan memicu terjadinya karies gigi. Selain itu, terdapat faktor-faktor yang mempengaruhi terjadinya karies gigi, misalnya makanan, keturunan, ras, air ludah, mikroorganisme, plak, jenis kelamin, usia, dan tingkat ekonomi (Irma, 2013). Studi Irma (2013) juga menemukan bahwa konsumsi makanan kariogenik yang terlalu sering menyebabkan peningkatan produksi asam sehingga mengakibatkan struktur email gigi yang sering terlarut dapat mengakibatkan karies gigi.

Studi pendahuluan yang dilakukan pada penelitian saat ini menunjukkan bahwa $70 \%$ anak usia sekolah di Sepatan mengalami karies gigi karena konsumsi makanan kariogenik yang tinggi dan jarang menggosok gigi. Hal ini sejalan dengan penelitian Kartikasari (2014) bahwa tingkat konsumsi makanan kariogenik tinggi (73\%). Selain itu, penelitian sebelumnya juga menemukan bahwa tingkat konsumsi makanan kariogenik yang tinggi pada anak usia sekolah (Indah, 2013; Rosidi, 2014). Penelitian Rosidi (2014) dan Alifiani (2017) menemukan bahwa terdapat hubungan yang signifikan antara konsumsi makanan kariogenik dan kejadian karies gigi. Namun, inkonsistensi hasil ditemukan pada penelitian Cruvinel (2010) yang menunjukkan bahwa pola makan tidak memiliki hubungan yang signifikan terhadap kejadian karies gigi.

Berdasarkan latar belakang tersebut, bahwa masih adanya inkonsistensi hasil terkait karies gigi 
Faletehan Health Journal, 6 (1) (2019) 25-29

www. journal.Ippm-stikesfa.ac.id/ojs/index.php/FHJ

ISSN 2088-673X | 2597-8667

yang dapat disebakan oleh perbedaan karakteristik anak usia sekolah dan minimnya penelitian terkait karies gigi di wilayah Sepatan, maka peneliti tertarik untuk melakukan penelitian "Risiko Kejadian Karies Gigi ditinjau dari Konsumsi Makanan Kariogenik pada Anak Usia Sekolah di Kabupaten Tangerang”.

\section{Metode Penelitian}

Penelitian ini merupakan penelitian deskriptif analitik menggunakan metode deskritif korelatif dengan desain cross sectional yang bertujuan untuk melihat hubungan antara konsumsi makanan kariogenik dengan resiko kejadian karies gigi. Populasi anak usia sekolah di SDN I Sepatan kelas I dan kelas II sebanyak 274 responden. Sampel pada penelitian ini diambil sebanyak 163 responden yang mengalami risiko karies gigi di SDN 1 Sepatan di Kabupaten Tangerang dengan menggunakan alat ukur risiko karies gigi yaitu cariogram yang sudah diadaptasi oleh peneliti menjadi lembar ceklis risiko karies gigi. Kuesioner konsumsi makanan kariogenik sudah diadaptasi oleh peneliti dari Cruvinel et al. (2010) dan sudah dilakukan uji validitas dan rebilitas.

Pengelolaan dan analisis data hasil penelitian menggunakan software komputer. Karakteristik responden, tingkat konsumsi makanan kariogenik, dan risiko kejadian karies diukur dengan distribusi frekuensi. Hubungan antara konsumsi makanan kariogenik dan risiko kejadian karies dianalisis dengan pendekatan uji bivariat, dengan uji chi square.

\section{Hasil dan Pembahasan}

Tabel 1. menunjukkan bahwa karakteristik tingkat konsumsi makanan kariogenik dengan risiko karies gigi yaitu mayoritas pada usia 7 tahun sebanyak 54,6\%, perempuan sebanyak 51,5\%, tingkat konsumsi makanan kariogenik tinggi sebanyak $55,8 \%$ dan risiko tinggi karies gigi sebanyak $76,7 \%$.

Hasil uji Chi-square pada tabel 2. menunjukkan adanya hubungan yang signifikan antara tingkat konsumsi makanan kariogenik dan risiko kejadian karies gigi $\left(\mathrm{X}^{2}(1, \mathrm{~N}=163)=14,51, p<.01\right)$. Hasil uji statistik menunjukkan bahwa tingkat konsumsi makanan kariogenik yang rendah cenderung akan menurunkan risiko kejadian karies gigi pada anak usia sekolah.

Tingkat konsumsi makanan kariogenik yang tinggi cenderung akan meningkatkan risiko kejadian karies pada anak usia sekolah. Hasil tersebut dapat disebabkan oleh perilaku anak usia sekolah yang gemar mengkonsumsi makanan yang kurang baik dan kurang mengutamakan kesehatan gigi di SDN I Sepatan. Jenis makanan kurang baik untuk kesehatan gigi, misalnya seperti cokelat, minuman berwarna dan makanan yang bersifat lengket merupakan termasuk jenis makanan kariogenik. Pihak sekolah telah menghimbau pada siswa-siswi untuk membawa makanan sehat dari rumah dan tidak jajan sembarang. Namun, masih terdapat siswa-siswi yang mengkonsumsi makanan seperti gulali, chiki, minuman berwarna, coklat, lidi-lidian, permen dan makanan kariogenik lain yang ada di lingkungan sekolah.

Tabel 1.Distribusi Frekuensi Karakteristik Tingkat Konsumsi Makanan Kariogenik dan Risiko Karies Gigi Responden ( $\mathrm{N}=163)$

\begin{tabular}{lcc}
\hline $\begin{array}{c}\text { Karakteristik } \\
\text { Responden }\end{array}$ & n & \% \\
\hline Usia & & \\
6 tahun & 65 & 39,9 \\
7 tahun & 89 & 54,6 \\
$\quad 8$ tahun & 9 & 5,5 \\
Jenis Kelamin & & \\
$\quad$ Laki-laki & 79 & 48,5 \\
$\quad$ Perempuan & 84 & 51,5 \\
Tingkat Konsumsi & & \\
Makanan Kariogenik & & \\
$\quad$ Tinggi & 91 & 55,8 \\
$\quad$ Rendah & 72 & 44,2 \\
Risiko Karies Gigi & & \\
$\quad$ Risiko Tinggi & 125 & 76,7 \\
$\quad$ Risiko Rendah & 38 & 23,3 \\
\hline
\end{tabular}

Tabel 2. Hubungan antara Tingkat Konsumsi Makanan Kariogenik dengan Risiko Karies Gigi (N=163)

\begin{tabular}{ccccc}
\hline Tingkat Konsumsi & \multicolumn{2}{c}{ Resiko Kejadian Karies Gigi } & \multirow{2}{*}{$x^{2}$} & $(I)$ \\
\cline { 2 - 3 } Makanan Kariogenik & Rendah & Tinggi & & \\
\hline Rendah & $27(3.8)$ & $45(-3.8)$ & & $14.5^{* * *}$ \\
Tinggi & $11(-3.8)$ & $80(3.8)$ & & 0,08 \\
\hline
\end{tabular}


Hal ini sejalan dengan penelitian yang dilakukan Rosidi et al. (2014) yang dilakukan di SDN I Gogodalem yang mengungkapkan bahwa terdapat hubungan yang signifikan antara konsumsi makanan kariogenik dan kejadian karies gigi pada anak usia sekolah. Konsistensi hasil juga ditemukan pada penelitian Kartikasari (2014), Talibo (2016), Novianus (2017) yang mengungkapkan bahwa konsumsi makanan kariogenik mempunyai hubungan yang signifikan dengan kejadian karies gigi pada anak usia sekolah. Hasil tersebut dapat disebabkan karena adanya kesamaan karakteristik anak usia sekolah yang memiliki pola konsumsi makanan kariogenik yang sama di lingkungan sekolahnya. Selain itu, wilayah sekolah pada penelitian terdahulu dan saat ini belum memiliki kantin sehat dan belum menerapkan peraturan terkait jenis jajanan yang boleh dijual di lingkungan sekolah.

Tingginya tingkat konsumsi makanan kariogenik cenderung akan meningkatkan risiko karies gigi pada anak usia sekolah, karena konsumsi makanan kariogenik yang mempunyai sifat manis dan lengket dapat menyebabkan tersisanya makanan di dalam mulut. Sisa makanan tersebut mengendap dan berfermentasi menjadi asam sehingga menimbulkan plak pada gigi yang dapat meningkatkan risiko karies gigi. Oleh karena itu, promosi kesehatan mengenai makanan kariogenik dan pentingnya perawatan gigi yang benar perlu disosialisasikan pada semua pihak di sekolah.

\section{Simpulan}

Berdasarkan hasil penelitian dan pembahasan mengenai hubungan konsumsi makanan kariogenik dengan risiko karies gigi pada anak usia sekolah di Kabupaten Tangerang dapat disimpulkan bahwa siswa yang memiliki tingkat konsumsi makanan kariogenik tinggi akan memiliki risiko tinggi untuk terjadinya karies gigi, sedangkan siswa yang rendah konsumsi makanan kariogenik akan mempunyai risiko yang rendah terhadap kejadian karies.

Hasil penelitian ini dapat dijadikan data dasar dalam mengembangkan penelitian selanjutnya terkait prediktor kejadian karies gigi dan sebagai data untuk mengembangkan promosi kesehatan berkaitan dengan pencegahan karies gigi pada anak usia sekolah.

\section{Referensi}

Alifiani, H \& Jamaludin (2017). Hubungan Kebiasaan Gosok Gigi dan Konsumsi Makanan Kariogenik dengan Kejadian Karies Gigi Pada Anak Usia Sekolah Dasar. Faletehan Health Journal, 4 (4) (2017) 228-232.

Cruvinel, V. R., Gravina, D. B., Azevedo, T. D., Bezerra, A. C., Toledo, O. A. (2010). Prevalence Of Dental Caries and Caries Related Risk Factor In Premature and Tom Children. Braz Oral Res. Vol. 24(3):329-35.

Departemen Kesehatan Republik Indonesia. 2013. "Laporan Hasil Riset Kesehatan Dasar". Jakarta Badan Penelitian dan Pengembangan Kesehatan. http://www.depkes.go.id/index.

Glodny, B., Nasseri, P., Crismani, A., Schoenherr, E., Luger, A. K., Bertl, K., \& Petersen, J. (2013). The occurrence of dental caries is associated with atherosclerosis. Clinics (Sao Paulo, Brazil), 68(7), 946-53.

Hasturk, H., \& Kantarci, A. (2015). Activation and resolution of periodontal inflammation and its systemic impact. Periodontology 2000, 69(1), 255-73.

Irma I, (2013). "Penyakit Gigi, Mulut dan THT". Yogyakarta : Nuha Medika.

Kartikasari, H., \& Nuryanto, N. (2014). Hubungan Kejadian Karies Gigi dengan Konsumsi

Kementrian Kesehatan Republik Indonesia. (2013). Riset kesehatan Dasar: Badan Penelitian dan Pengembangan Kesehatan Diakses melalui www.litbang.depkes.go.id/ rkd2013/Laporan_Riskesdas2013.pd

Makanan Kariogenik dan Status Gizi pada Anak Sekolah Dasar (Studi Pada Anak Kelas III dan IV SDN Kadipaten I dan II Bojonegoro).Journal of Nutrition College, 3(3), 414-421. Doi:http://dx.doi.org/10.14710/ jnc.v3i3.6605.

Novianus, C. (2017). Hubungan Karakteristik dan Konsumsi Makanan Kariogenik dengan Kejadian Karies Gigi Pada Siswa Umur 11-12 Tahun di Sekolah Dasar Negeri Terpilih Wilayah Kerja Puskesmas Taktakan Kota Serang. ARKESMAS (Arsip Kesehatan Masyarakat), 1(2), 83-87. Retrieved from https://journal.uhamka.ac.id/index.php/ar kesmas/article/view/508. 
Faletehan Health Journal, 6 (1) (2019) 25-29

www. journal.Ippm-stikesfa.ac.id/ojs/index.php/FHJ

ISSN 2088-673X | 2597-8667

Nugroho, P. (2011). Penyaki Periodontal Sebagai Penyebab Sebagai Penyebab Penyakit Jantung Koroner di Bangsal Jantung RSUP Dokter Kariadi. Jurnal Media Medika Muda. Diakses dari: $\quad$ https://media.neliti.com/media/ publications/106709-ID-penyakit-periodontalsebagai-penyebab-pe.pdf

Prakoso, H. M. (2016). Hubungan antara kebiasaan konsumsi makanan kariogenik dan menggosok gigi pada anak serta pengetahuan ibu dengan kejadian karies gigi di paud taman ceria Surakarta. Diakses dari: http://eprints.ums.ac.id/47495/1/NASKAH\%2 OPUBLIKASI.pdf

Rosidi, A., Haryani, S., Adimayanti, E. (2014). Hubungan antara Konsumsi Makanan Kariogenik dengan Kejadian Karies Gigi pada Anak SDN I Gogodalem Kecamatan Bringin Kabupaten Semarang. Prosiding Seminar Nasional Hasil-hasil Penelitian \& Pengabdian Universitas Muhammadiyah Semarang. Diakes dari: https://jurnal.unimus.ac.id/index.php/ psn12012010/article/view/1235/1288
Talibo, R. S., Mulyadi., Bataha, Y. (2016). Hubungan Frekuensi Konsumsi Makanan Kariogenik \& Kebiasaan Menggosok Gigi dengan Kejadian Karies Gigi Kelas III di SDN 1 dan 2 Sonua. e-Journal Keperawatan (e-KP) Vol. 4(1): 1-8.

World Health Organization. (2019). Oral health information system. Diakses dari: https://www.who.int/oral_health/action/inform ation/surveillance/en/ 